\title{
Fulminant Hepatitis Failure in Adults and Children from a Public Hospital in Rio de Janeiro, Brazil
}

\author{
Damião Carlos Moraes dos Santos ${ }^{1}$, José Manoel da Silva Gomes Martinho², Lucio Filgueiras Pacheco-Moreira ${ }^{2}$, Cristina \\ Carvalho Viana de Araújo ${ }^{2}$, Barbara Cristina Euzebio Pereira Dias de Oliveira ${ }^{2}$, Barbara Vieira Lago ${ }^{3}$, Marcelo Alves Pinto ${ }^{1}$ and \\ Vanessa Salete de Paula ${ }^{1}$ \\ ${ }^{1}$ Laboratório de Desenvolvimento Tecnológico em Virologia, IOC, FIOCRUZ; ${ }^{2}$ Hospital Geral de Bonsucesso; ${ }^{3}$ Laboratório de Virologia \\ Molecular, IOC, FIOCRUZ; Rio de Janeiro, RJ, Brazil
}

\begin{abstract}
Fulminant hepatic failure (FHF) is characterized by massive hepatocellular injury, whose physiopathology is still unclear. Hepatitis B (HBV) is probably the most common viral cause of FHF, while hepatitis A (HAV) virus seem occurs less frequently. However, the host and viral factors that determine the outcome of these infections are poorly understood. In the present study, viral load and genotyping determining regions of HAV and HBV genomes were sequenced. Eight FHF patients and one patient with severe acute hepatitis (SAH) were included. Liver and blood samples were collected during liver transplantation or necropsy procedures. HAV-RNA and HBV-DNA were extracted from serum, biopsy and paraffin liver. Nucleotide sequencing of HAV-RNA was performed from VP1/2A and HBVDNA from PreS/S region. The amplified samples were quantified by Real-Time PCR. The cases of HAV infection were due to subgenotype IA. The cases of $\mathrm{HBV}$ infection were due to genotype A2 and D4. The case of HAV/HBV coinfection was infected by genotype IA and D3. Hepatitis A and B infection were associated with genotypes most prevalent in Brazil. In hepatitis A infection the mean of period evolution was 13 days. In hepatitis B, FHF patients infected by genotype D have a shorter period of evolution than FHF patients infected by genotype A (mean 15 v. 53 days). There was no association with genotype-determining region with the severity of hepatitis, however nucleotide differences and high viral load could be observed among FHF.
\end{abstract}

Key-Words: Fulminant hepatitis failure, hepatitis A virus (HAV), hepatitis B virus (HBV) and genotype and viral load.

Fulminant hepatic failure (FHF) is a dramatic clinical syndrome resulting from the massive death of liver cells not adequately balanced by regenerative activity. It is usually characterized by the abrupt appearance of encephalopathy and coagulation disturbances in individuals with previously normal hepatic function. In these cases, liver transplantation is the only definitive therapeutic alternative. Several etiologies have been described to induce FHF. Among them, hepatitis A virus (HAV) and hepatitis B virus (HBV), and although rare, FHF presents a mortality rate of up to $80 \%$ without liver transplantation [1]. HBV infection is the most important cause of FHF, occurring in approximately $1 \%$ of the cases, while HAV occurs less frequently, from $0.5 \%$ to $1 \%$ of the cases. However, the majority of the patients present a self-limited course of hepatitis A and 5\% to $10 \%$ of patients infected by HBV presents chronic course. In both cases, the clinical outcome may depend on several factors such as age and individual genetic characteristics. Nevertheless, the association between genotypes, clinical course, and excessive host response associated to marked reduction in viral load has been under discussion [2-4]. HAV is classified in the genus Hepatovirus within the Picornaviridae family. The genome is a positive strand RNA with approximately 7,500 nucleotides consisting of a 5' non-

Received on 10 April 2009; revised 11 July 2009.

Address for correspondence: Dr. Vanessa Salete de Paula - Laboratório de Desenvolvimento Tecnológico em Virologia. IOC - Oswaldo Cruz Foundation. Av. Brasil 4365, Rio de Janeiro, RJ, Brazil. Zip code: 21045900. Phone: 2155 2562-1876 - Fax: 2155227063 97. E-mail: vdepaula@ioc.fiocruz.br.

The Brazilian Journal of Infectious Diseases 2009;13(5):323-329. (C) 2009 by The Brazilian Journal of Infectious Diseases and Contexto Publishing. All rights reserved. translated region, both structural and non-structural protein regions and a 3' non-translated region [5]. HAV strains correspond to a single serotype and have been classified into six genotypes [6,7].

HBV is a member of the Hepadnaviridae family, with a partially double stranded DNA genome that presents a very high genetic variability. Based on the nucleotide sequences, HBV has been classified into eight genotypes designed A through $\mathrm{H}$ which differ by more than $8 \%[8,9]$. Due to its genetic diversity, a number of subgenotypes were described [9]. HBV genotypes and the majority of the subgenotypes show a distinct geographic distribution and early studies have been correlated to the severity of liver disease with the presence of some HBV genotypes [10].

Despite the advances in the understanding of the HAV and $\mathrm{HBV}$, there is no data concerning the association between genotypes and fulminant hepatitis in Brazil. To explore if there are genotype differences in HAV and HBV that affect disease severity, the nucleotide sequences of genotype regions of the viruses from patients with extensive liver lesion were analyzed.

\section{Material and Methods}

Between January of 2003 and December of 2006, 33 patients with fulminate hepatic failure (FHF) were seen at the Liver Clinic/ Hospital Geral de Bonsucesso in Rio de Janeiro, Brazil. Among them 27\% (9/33) were caused by viral hepatitis, eight with fulminant hepatic failure (FHF) and one patient with severe acute hepatitis (SAH). The clinical diagnostic of the patients were according to O'Grady of King's College [1]. Thus, the cases were classified as fulminant hepatitis by development encephalopathy between 7 days and 12 weeks from the onset 
of jaundice. The case of SAH, however, presented coagulopathy without encephalopathy. Three cases of FHF were induced by HAV and five of them were induced by $\mathrm{HBV}$. The case of SAH was induced by co-infection HAV/ HBV. Clinical and serological date from FHF patients such as prothrombin time activity (PTA), alanine aminotransferase (ALT), total bilirrubin and encephalopathy score were obtained from medical records during the intensive care period. The protocol of procedures was submitted to the Ethic Committee (Governmental Human Research) and reviewed at the Institutional Reviewer Board (CEPFIOCRUZ.n²2/03).

\section{Liver and Blood Samples}

Liver and blood samples were obtained during liver transplantation procedures, except for patients that did not undergo liver transplantation, in these cases, only blood samples were obtained to study. Also, blood samples of three patients were not available, because they were retrospective cases; however their liver sections had been fixed in $10 \%$ buffered formalin and embedded in Paraplast, dehydrated in a graded series of ethanol and embedded in paraffin. The same above procedure was conduced for liver sample obtained by necropsy. In the case of fresh liver samples, fragments of hepatic explant were obtained and immediately after liver collection were snap frozen in liquid nitrogen-cooled $\left(-196^{\circ}\right.$ C).

Serological Markers and Biological Test

All the patients were tested for viral hepatitis: anti-HAV IgM (Abbot, USA), HBsAg (Dia Sorin, Italian), anti-HBc IgM (BioKit, Spain), anti-HCV (Dia Sorin, Italian) and anti-HEV (BioKit, Spain).

Treatment of Paraffin-Embedded Liver Samples to Viral Genome Extraction

The treatment of paraffin-embedded liver samples for viral genome extraction was performed according to previously described methods [11]. Briefly, two sections of $7 \mu \mathrm{m}$ were deparaffinized overnight using xylene at $65^{\circ} \mathrm{C}$, followed by washes in absolute ethanol.

\section{HAV RNA Extraction and PCR Amplification}

RNA extraction and reverse transcription were realized by using a commercial assay QIAamp Viral RNA (QIAGEN, Valencia, CA, USA). Viral RNA was extracted from $140 \mu \mathrm{L}$ of concentrated water samples and $60 \mu \mathrm{L}$ of RNA were eluted. The cDNA was prepared at $50^{\circ} \mathrm{C}$ over the course of $1 \mathrm{~h}$ using $10 \mathrm{~mL}$ of RNA, random primers (Life Technologies, Gaithersburg, MD, USA) and the Super Script III reverse transcriptase (Life Technologies). After reverse transcription, the VP1/2A junction region of the HAV genome was amplified using nested PCR as described elsewhere [12].The PCR products were separated on $1.5 \%$ agarose gels and stained with ethidium bromide.
Quantification of HAV RNA

HAV RNA was quantified by real time PCR (TaqMan technology), using a standard curves previously described [13]. Amplification assays were performed in a final volume of $25 \mu \mathrm{L}$ of TaqMan universal Mastermix (Applied Biosystems), containing $5 \mu \mathrm{L}$ of extracted cDNA, $1.25 \mu \mathrm{L}$ of assay containing forward primer (50CTGCAGGTTCAGGGTTCTTAAATC-30, nt 86 to 109) reverse primer (50-GAGAGCCCTGGAAGAAAGAAGA-30, nt 219-240) and HAV-probe (FAM 50ACTCATTTTTCACGCTTTCTG- 30, nt 198-218). The detection limit of the assay was 14 copies/reaction. The thermal cycling conditions consisted of denaturation for 10min at $94^{\circ} \mathrm{C}$ followed by 40 cycles of $15-\mathrm{s}$ at $94^{\circ} \mathrm{C}$ and a final 1 -min cycle at $60^{\circ} \mathrm{C}$.

\section{HBV DNA Extraction and PCR}

Viral DNA was extracted from serum or liver by using thephenol-chloroform method after treatment with proteinase $\mathrm{K}$, as described previously [14]. The HBV pre-S/S genomic region was amplified by using sense primer PS1 (5'CCATATTCTTGGGAACAAGA-3', nt 2826-2845) and a mix of antisense primers S2 (5'-GGGTTTAAATGTATACCCAAAGA3', NT 841-819) and (5' GTATTTAAATGGATACCCACACAGA3', nt 841-819), able to amplify all HBV genotypes. PCR assays were performed under the following conditions: 35 cycles of $94^{\circ} \mathrm{C}$, $30 \mathrm{~s} ; 52^{\circ} \mathrm{C}, 1 \mathrm{~min} ; 72^{\circ} \mathrm{C}, 2 \mathrm{~min}$; followed by a final elongation temperature at $72^{\circ} \mathrm{C}$ for $7 \mathrm{~min}$. Amplification products $(50 \mu \mathrm{L})$ were loaded on a $1.5 \%$ agarose gel, electrophoresed, stained with ethidium bromide and visualized under UV light.

\section{Quantification of HBV DNA}

HBV DNA was quantified by real time PCR (TaqMan technology), using a panel of reference sera containing given numbers of HBV DNA molecules, under the conditions described previously [15], with somemodifications. Amplification assays were performed at a final volume of $25 \mu \mathrm{L}$ of TaqMan universal Mastermix (Applied Biosystems), containing $2 \mu \mathrm{L}$ of extractedDNA, $1 \mu \mathrm{L}$ of sense primer (5'-GGACCCCTGCTCGTGTTACA-3', nt position 184 to 203) and antisense (5'AGAGAAGTCCACCMCGAGTCTAGA-3',ntposition 273to 249) primers designed in the $\mathrm{S}$ region and $0.3 \mu \mathrm{M}$ of probe (5'-FAM TGTTGACAARAATCCTCACAAATACCRCAGA-TAMRA-3', nt position 218-247). After initial incubation steps of $2 \mathrm{~min}$ at $50^{\circ} \mathrm{C}$ and 10 min at $95^{\circ} \mathrm{C}$, PCR assays consisted of 50 step cycles of $15 \mathrm{~s}$ at $95^{\circ} \mathrm{C}$ and 60 s at $60^{\circ} \mathrm{C}$. Reactions were performed in a 7700 sequence detection system (Applied Biosystems). The detection limit of the assay was 10 copies/mL.

\section{Direct Sequencing of HAV and HBV}

Amplicons of expected size of HAV (247 bp) and HBV (1200 bp) were purified using the QIAquick PCR Purification Kit (QIAGEN) according to the manufacturer's instructions. Direct nucleotide sequencing was performed in both directions using dye terminator reaction with dRhodamine terminator 
reagents. Sense and anti-sense primers were used in the second round of PCR. Results were analyzed in an ABI Prism 3370 machine (Applied Biosystems, Foster City, CA, USA). Sequences reported in this paper have been deposited in the GenBank sequence database under the accession numbers EU395777-EU395785.

\section{Sequence Analysis}

The DNA star package was used for nucleotide alignment and for establishing amino acid sequences. Multiple alignments were initially performed with the Clustal $\mathrm{X}$ program [16]. Further adjustments were performed manually using visual correction based on sequence comparison generated with the Bioedit program. Phylogenetic trees were created using the neighbor-joining method and the Kimura two-parameter model by Felsenstein PHYLIP phylogenetic Inference Package, version 3.5. with MEGA 2.1 software [17]. Phylogenetic tree reliability was assessed by bootstrap re-sampling $(1,000$ pseudoreplicates).

\section{Results}

Serological Markers of Hepatitis A and Hepatitis B

Among the patients involved in this study, three had serological evidence of acute Hepatitis (anti-HAV IgM positive), five had evidence of acute hepatitis B (HBsAg and anti-HBc IgM positive) and one had serological evidence of acute co-infection HAV/HBV (anti-HAV IgM and HBsAg). All patients were negative for anti-HCV and anti-HEV IgM and none of them, had nor related use of hepatotoxic drugs such as acetaminophen, neither autoimmunity antibodies nor metabolical diseases.

Clinical and Biochemical Data from Fulminant Hepatic Failure Patients Induced by HAV Infection

The clinical characteristics of patients analyzed for HAV genotype are summarized in the Table 1. Among the patients with HAV infection, the time of evolution (period passed between the first signals and development of encephalopathy) ranged between 10 and 20 days; the mean was 13 days. Two patients died (HAV-3-03 and HAV-8-06); the patient HAV-3-03 who died after liver transplantation was a 3 year old child; the analyzed sample was paraffin liver. The patient HAV-7-05 recovered after liver transplantation and the analyzed samples were fresh liver and serum. Among the two patients who underwent liver transplantation (HAV-3-03 and HAV-7-05) the encephalopathy grade was IV.

\section{HAV Mutations and Viral Load}

In this study, the viral RNA was extracted from paraffin liver, serum and liver explants. Serum was investigated in two samples of hepatitis A (HAV-8-06, HAV-7-05). In the first one the viral load was $2.36 \times 10^{5}$ copies $/ \mathrm{mL}$ and the second patient who recovered after liver transplantation had $3.07 \times 10^{4}$ copies $/ \mathrm{mL}$ in peripheral blood, in this latter case, $1.65 \times 10^{6} \mathrm{copies} / \mathrm{mL}$ in fresh liver sample collected from the explant were detected. It was not possible to measure the viral load from patient whose the HAV RNA had been extracted from paraffin liver. All of the three patients with fulminant hepatitis A under study were infected with genotype IA (Figure 1). Nucleotide sequences (210 nt) of the VP1/2A junction region of the samples were 97.4-99.2\% homologous, no specific substitutions between fulminant hepatitis cases were observed.

The samples were also sequenced in 5'NTR (400nt) and compared with samples from acute hepatitis of sporadic cases sequenced previously in Brazil and other countries. In 5'NTR less nucleotide substitutions were found in patients with fulminant hepatitis than in patients with acute hepatitis.

Biochemical and Serological Data from Fulminant Hepatic Failure Patients Induced by HBV Infection

The clinical characteristics of patients analyzed for HBV genotype are also summarized in the Table 1 . The mean age among the patients with HBV infection was 45 years old, and the time of evolution ranged from 8 to 56 days, a mean of 32 days. Four patients died, two of them, after the liver transplantation. The encephalopathy score among fulminant hepatitis B ranged from II to IV and the ALT values were higher than $631 \mathrm{UI} / \mathrm{L}$ in all patients.

\section{HBV Mutations and Viral Load}

In this study, the viral loads among patients with fulminant hepatitis range from undetermined to $1.24 \times 10^{7}$ copies/mL (Table I), none of them received antiviral therapy. In three patients that had the viral load measured in serum samples, the number of copies per milliliters was $10^{5}$. In four patients infected with HBV the DNA was extracted from liver tissue, in the patient HBV-2-03 the viral load from liver fixed with paraffin was $5.59 \times 10^{5}$ copies $/ \mathrm{mL}$ and in the patient HBV-6-05 the viral load from fresh liver was $1.24 \mathrm{x}$ $10^{7}$ copies/mL.

Among the fulminant hepatitis B patients, the following HBV genotypes/subgenotypes distribution was found: A2 $(n=2), D 4(n=3)$. The isolates from this study were divergent among them (Figure 2). In genotype/subgenotype A2 the sequence variation was $0.2 \%$. In homology between genotype/subgenotype D4 was 90.2-95.4\%. Deduced amino acid sequence analysis of pre-S/S region showed that pre$\mathrm{S}$ and $\mathrm{S}$ regions displayed several aminoacid variations, when compared to sequence consensus encountered in genotype A and D, available in GeneBank database.

Biochemical and Hepatitis Markers from the Severe Acute Hepatitis Patient Induced by Co-Infection HAV/HBV

The co-infected HAV/HBV patient, who developed severe acute hepatitis, presented ten days of evolution time (between the first symptoms and coagulation disturbances), did not 


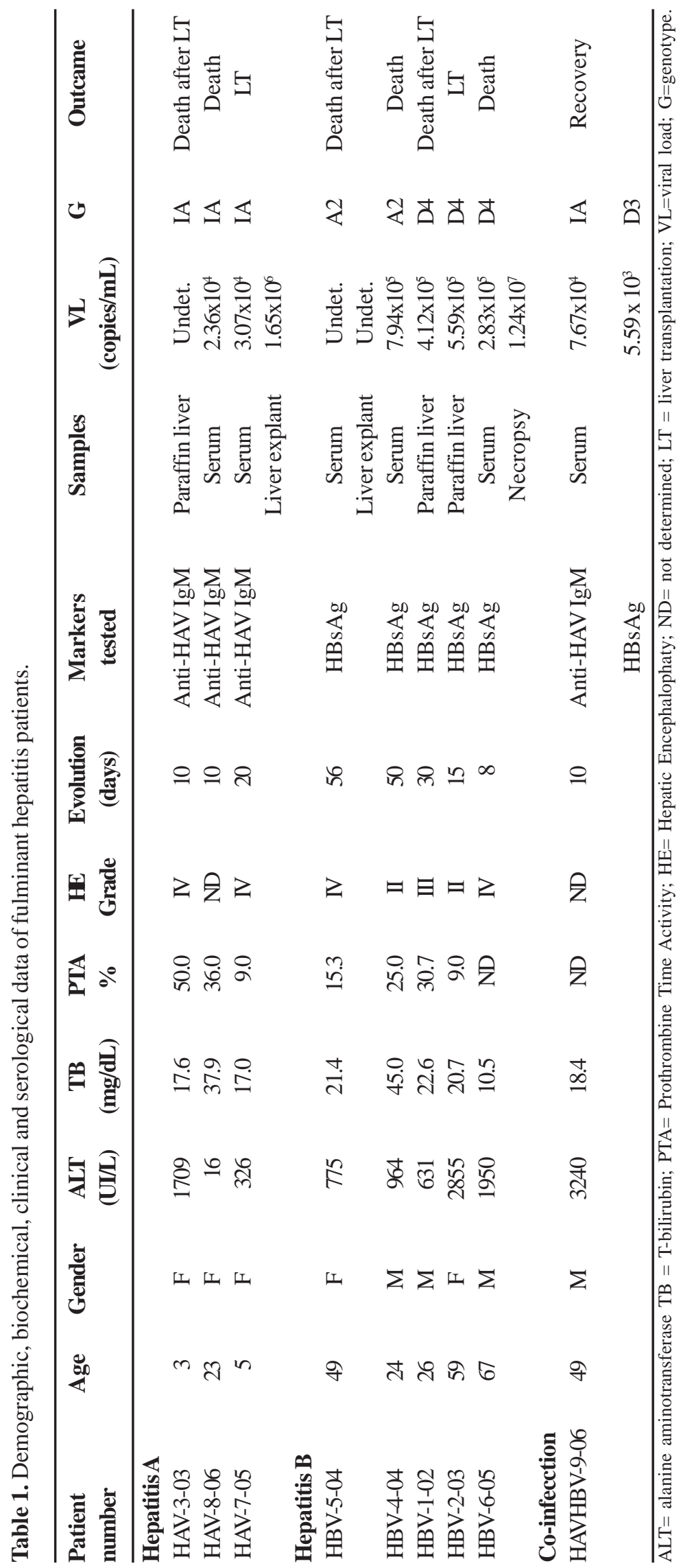

Figure 1. Phylogenetic tree based on 210-nt sequences of the VP1/2A region from Hepatitis A virus and depicting the genetic relatedness of isolates from this study (in bold) with other HAV strains previously characterized. The numbers at nodes indicate bootstrap percentages after 1,000 replications sampling. The horizontal bar provides a genetic distance scale.

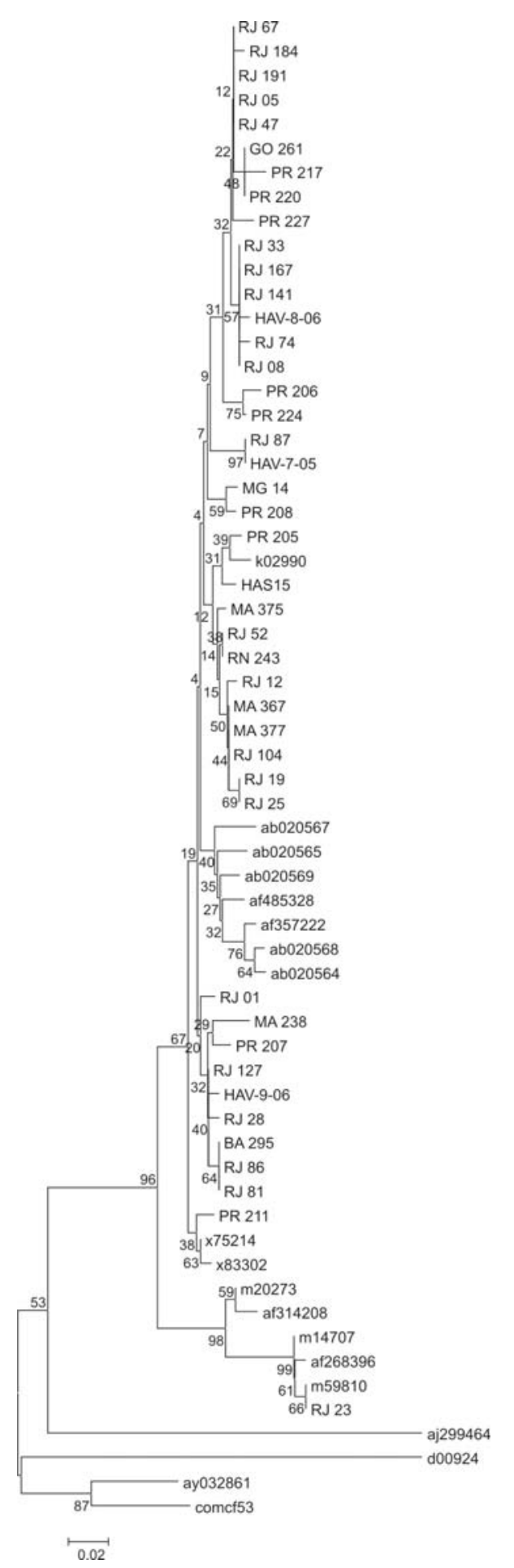


Figure 2. Phylogenetic tree based on 1200-nt sequences of the Pre S/S region from hepatitis B virus and depicting the genetic relatedness of isolates from this study (in bold) with other HBV strains previously characterized. The numbers at nodes indicate bootstrap percentages after 1,000 replications sampling. The horizontal bar provides a genetic distance scale.

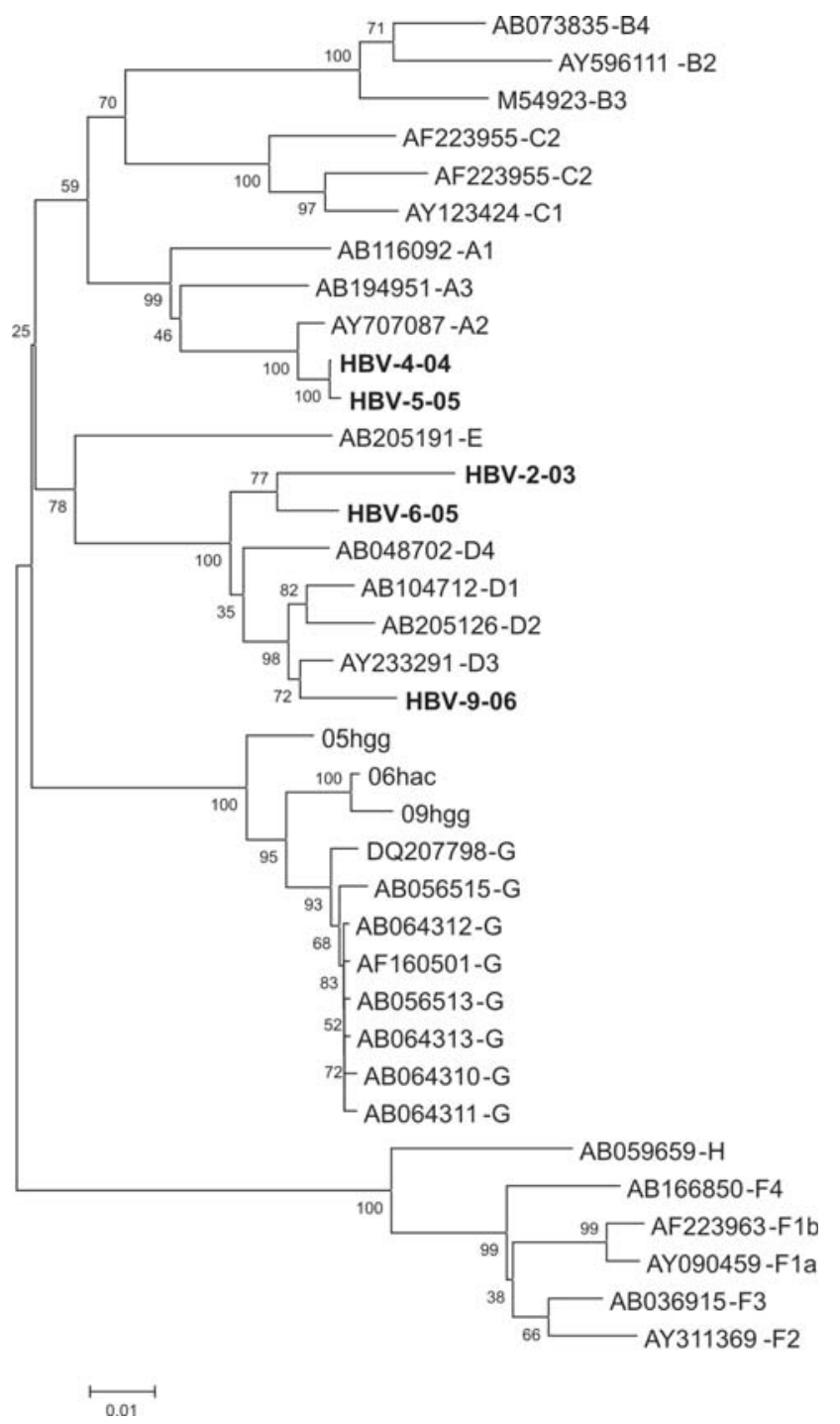

have early indicators of prognostic fulminant hepatic failure, classically did not develop encephalopathy and the PTA was not disposable in medical records. From this patient, only blood samples were analyzed.

\section{HAV and HBV Mutations and Viral Load in the Co-Infected Patient}

In the patient co-infected by HAV/HBV the viral load of HBV was $5.59 \times 10^{3}$ copies/mL and the genotype/subgenotype isolated was D3. The HAV viral load was $7.67 \times 10^{4}$ copies $/ \mathrm{mL}$ and the genotype isolated was also IA, as observed in other cases included in this study.

\section{Discussion}

The specific physiopathology of fulminant hepatic failure induced by viruses has not yet been well described, but some studies have suggested that the disease severity induced by these viruses may be related to genetic variability $[2,18]$. The clinical course severity of hepatitis A is associated with the age, being less severe in younger children, while that in older children and adults these diseases tend to be more symptomatic [19]. In this study 33\% of FHF were caused by $\mathrm{HAV}$, the mean age of fulminant hepatitis A was 13; two of the patients were less than five years old; previous studies have shown that hepatitis $\mathrm{A}$ is the most common detectable cause of fulminant hepatic failure in children [20-23]. A retrospective study showed that HAV is the most frequent aetiological agent of acute liver failure, being associated with $39 \%$ of cases eligible for liver transplantation [23].

All hepatitis A patients, including the patients coinfected with hepatitis B, were infected by genotype IA, the more prevalent in Brazil [24]; suggesting that in areas where the subgenotype IA is the most prevalent, FHF is associated with this genotype. There was no association with genotype-determining region with the severity of hepatitis A $[3,4]$, however nucleotide differences can be observed among FHF [20].

The comparison of 5'NTR sequences showed less nucleotide substitutions in relation to samples from acute hepatitis A. However, Fujiwara and colleagues showed that patients can develop FHF independent of the number of nucleotide substitutions in 5' NTR of HAV and the number of substitutions encountered in the 5' central region does not appear to be the unique factor that defines the outcome of the clinical course. The variations in the 5' NTR region may influence replication of the virus and affect the virulence [2].

Few data are available concerning hepatitis A viral load and fulminant hepatitis failure. Rezende and colleagues, 2003, who showed that low viral load was the main factor associated with FH, suggested that HAV-related liver failure is due to an excessive host response associated with a marked reduction in viral load; in our study one sample had undetectable viral load, the recovery from paraffin liver of HAV RNA is difficult due to degradation. In fresh liver the viral load was $1.65 \times 10^{6}$ copies/mL; higher viral loads in patients with fulminant and severe hepatitis A may be associated with the pathogenesis of disease severity [25]. In this study, viral loads measured in serum samples were $10^{4}$ copies/mL, these patients had the same viral loads previously reported for patients with fulminant hepatitis A [25].

Hepatitis B is endemic in the Brazilian Amazon Basin and several studies have revealed the association of HBV and fulminant hepatitis [26]. However, this is the first study, in Brazil, correlating HBV genotypes with FHF targeting to the 
S-gene encoding the hepatitis B surface antigen. Hepatitis B is probably the most common viral cause of FHF and the incidence may be underestimated. As in other studies, hepatitis B virus prevails in patients with FHF and is responsible for the majority of cases [27-29].

In this study, genotypes A and D were associated with fulminant hepatitis; however these genotypes are common in patients with acute hepatitis B in Brazil. The FHF samples displayed several amino acid variations, found in sequence consensus encountered in genotype $\mathrm{A}$ and D. As observed in India [30] and in our study, the HBV genotype $\mathrm{D}$ was more prevalent than $\mathrm{A}$ among FHF. In east-Asian countries where genotypes $\mathrm{B}$ and $\mathrm{C}$ are found to be dominant, fulminant hepatitis genotype $\mathrm{C}$ is associated with the more aggressive clinical course related to chronic hepatitis with evolution to cirrhosis [31-34]. The genotype $C$ has a short course of fulminant hepatitis in comparison to genotypes A, B and D [35]. However, the FHF patients infected by genotype $\mathrm{D}$ have a shorter period of evolution than FHF patients infected by genotype A (mean 15 vs. 53 days), suggesting that genotype D has a fast progression course.

In our study in four out of five patients infected with HBV the viral load measured was $10^{5}$ copies $/ \mathrm{mL}$. A previous study showed that almost all of the patients who remained HBeAg-positive had HBV DNA levels that were persistently above $10^{5}$ copies/mL in serum sample [23,36]. The samples extracted from paraffin liver had the same viral load as the serum samples, these results showed that it is possible to recovery DNA from paraffin liver to quantify and genotype HBV in fulminate hepatitis cases.

In patient HBV-6-05 who had serum and biopsy analyzed, the viral load in liver was observed to be two logs higher than in the serum sample, showing a massive replication in liver; the HBV DNA was classified into genotype $\mathrm{D}$, the patient had a fast progression (8 days) to hepatic coma and death. The viral load of this patient was four logs higher than the case of SAH, which may suggests that the higher viral load may be related to poor clinical course and very fast progression to FHF.

In the patient co-infected with HAV and HBV the ALT values were the highest (3240 UI/L) and had a fast evolution, however the HBV viral load was the lowest, probably the immunologcial factors that cleared HAV infection contributed to the low replication of $\mathrm{HBV}$ and the recovery of patient.

In conclusion, hepatitis A and B infections are vaccinepreventable diseases and so a universal vaccination should be implemented to avoid fulminant hepatitis failure.

\section{Acknowledgements}

This study was supported by Oswaldo Cruz Foundation (FIOCRUZ), Brazilian National Council for Research (CNPq). We would like to thank the transplantation medical team of Hospital Geral de Bonsucesso, RJ-Brazil.

\section{References}

1. O’Grady J.G., Schalm S.W., Williams R. Acute liver failure: redefining the syndromes. Lancet 1993;342 (8866): 273-5.

2. Fujiwara K., Yokosuka O., Ehata T., et al. Association between severity of type A hepatitis and nucleotide variations in the 5' non-translated region of hepatitis A virus RNA: strains from fulminant hepatitis have fewer nucleotide substitutions. Gut 2002; 51: 82-8.

3. Fujiwara K., Yokosuka O., Imazeki F., et al. Analysis of the genotype-determining region of hepatitis A viral RNA in relation to disease severities. Hepatol Res 2003;25:124-34.

4. Rezende G., Roque-Afonso A.M., Samuel D., et al. Viral and clinical factors associated with the fulminant course of hepatitis A infection. Hepatology 2003;38:613-8.

5. Cohen J.T., Ticehurst J.R., Purcell R.H., et al. Complete nucleotide sequence of wild-type hepatitis A virus: comparison with different strains of hepatitis A virus and other picornaviruses. J Virol 1987; 61: 50-9.

6. Robertson B.H., Jansen R.W., Khanna B., et al. Genetic relatedness of hepatitis A virus strains recovered from different geographical regions. J Gen Virol 1992;73:136577.

7. Lu L., Ching K.Z., De Paula V.S., et al. Characterization of the complete genomic sequence of genotype II hepatitis A virus (CF53/Berne isolate). J Gen Virol 2004;85:2943-52.

8. Okamoto H., Imai H., Shimozaki M., et al. Nucleotide sequence of a cloned hepatitis B virus genome, subtype ayr: comparison with genomes of the other three subtypes. J Gen Virol 1986;67:2305-14.

9. Norder H., Courouce A.M., Magnius L.O. Complete genomes, phylogenetic relatedness, and structural proteins of six strains of the hepatitis B virus, four of which represent two new genotypes. Virology 1994;198:489-503.

10. Kidd-Ljunggren K., Miyakawa Y., et al. Genetic variability in hepatitis B viruses. J Gen Virol 2002;83:1267-80.

11. Chen B.F., Clejan S. Rapid preparation of tissue DNA from paraffin-embedded blocks and analysis by polymerase chain reaction. J Histochem Cytochem 1993;41:765-8.

12. De Paula V.S., Arruda E., Vitral C.L., Gaspar A.M. Seroprevalence of viral hepatitis in riverine communities from the Western Region of the Brazilian Amazon Basin. Mem Inst Oswaldo Cruz 2001;96:1123-8.

13. De Paula V.S., Diniz-Mendes L., Villar L.M., et al.Hepatitis A virus in environmental water samples from the Amazon Basin. Water Res 2007; 41: 1169-76.

14. Niel C., Moraes M.T., Gaspar A., et al. Genetic diversity of hepatitis B virus strains isolated in Rio de Janeiro, Brazil. J Med Virol 1994;44: 180-6.

15. Niesters H.G., De man R.A., Pas S.D., et al. Identification of a new variant in the YMDD motif of the hepatitis B virus polymerase gene selected during lamivudine therapy. J Med Microbiol 2002;51:695-9.

16. Thompson J.D., Gibson T.J., Plewniak F., et al. The CLUSTAL_X windows interface: flexible strategies for multiple sequence alignment aided by quality analysis tools. Nucleic Acids Res 1997;25:4876-82.

17. Kumar S., Tamura K., Jakobsen I.B., et al. MEGA2: molecular evolutionary genetics analysis software. Bioinformatics 2001;17:1244-5.

18. Sainokami S., Abe K. Sato A., et al. Initial load of hepatitis B virus (HBV), its changing profile, and precore/core promoter mutations correlate with the severity and outcome of acute HBV infection. J Gastroenterol 2007;42:241-9.

19. Hollinger F.B., Emerson S.U. Hepatitis A virus. In: Knipe DM, Howley PM, eds. Fields Virology. New York: Lippincott Williams \& Wilkins, 2001; 799-840.

20. Munné M.S., Vladimirsky S., Moreiro R., et al. Molecular characterization of hepatitis A virus in children with fulminant hepatic failure in Argentina. Liver Int 2007;28:47-53.

21. Aydoðdu S., Ozgenç F., Yurtsever S., et al. Our experience with fulminant hepatic failure in Turkish children: etiology and outcome. J Trop Pediatr 2003;49:367-70. 
22. Husain E., Al-Tawfiq J.A., Husain K. Epidemiology and outcome of severe hepatitis A infection in children in Kuwait. Med Princ Pract 2006;15:266-9.

23. Chu C.J., Lok A.S. Clinical utility in quantifying serum HBV DNA levels using PCR assays. J Hepatol 2002;36:54951 .

24. de Paula V.S., Lu L., Niel C., et al. Genetic analysis of hepatitis A virus isolates from Brazil. J Med Virol 2004;73:378-83.

25. Fujiwara K., Yokosuda O., Imazeki F., et al. Do High levels of replication contribute to fulminant hepatitis A? Liver Int 2005;25;194-5.

26. da Fonseca J.C. Hepatitis fulminant in Brazilian Amazon. Rev Soc Bras Med Trop 2004;37:93-5.

27. Ostapowicz G., Fontana R.J., Schiodt F.V., et al. U.S. Acute Liver Failure Study Group. Results of a prospective study of acute liver failure at 17 tertiary care centers in the United States. Ann Intern Med 2002;137:947-54.

28. Polson J., Lee W.M., American Association for the Study of Liver Disease. AASLD position paper: the management of acute liver failure. Hepatology 2005;41:1179-97.

29. Schiodt F.V., Davern T.J., Shakil A.O., et al. Viral hepatitisrelated acute liver failure. Am J Gastroenterol 2003;98:44853.
30. Chattopadhyay S., Das B.C., Hussain Z., Kar P. Hepatitis B virus genotypes in acute and fulminant hepatitis patients from north India using two different molecular genotyping approaches. Hepatol Res 2006;35:79-82.

31. Chan H.L., Tse C.H., Ng E.Y., et al. Phylogenetic, virological, and clinical characteristics of genotype $\mathrm{C}$ hepatitis B virus with TCC at codon 15 of the precore region. J Clin Microbiol 2006;44: 681-7.

32. Orito E., Ichida T., Sakugawa H., et al. Geographical distribution of hepatitis $\mathrm{B}$ virus (HBV) genotype in patients with chronic HBV infection in Japan. Hepatology 2001;34: 590-4.

33. Liu C.J., Kao J.H., Lai M.Y., et al. Precore/core promoter mutations and genotypes of hepatitis $\mathrm{B}$ virus in chronic hepatitis B patients with fulminant or sub-fulminant hepatitis. J Med Virol 2004;72:545-50.

34. Yusar R., Takahashi K., Dien B.V., et al. Properties of hepatitis B virus genome recovered from Vietnamese patients with fulminant hepatitis in comparison with those of acute hepatitis. J Med Virol 2000;61:23-8.

35. Joh R., Hasegawa K., Ogawa M., et al. Genotypic analysis of hepatitis $\mathrm{B}$ virus from patients with fulminant hepatitis: comparison with acute self-limited hepatitis. Hepatol Res 2003 Jun;26:119-24.

36. Benhava B., Assari S., Amini M., et al. HBV DNA load and chronic hepatitis infection in different stages. Hep Monthly 2005;5:123-7. 